\title{
Myocardial antioxidant and oxidative stress changes due to sex hormones
}

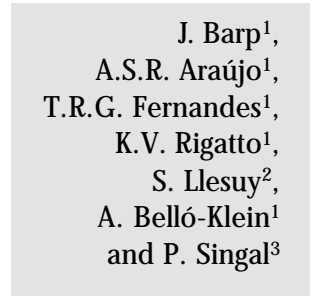

\author{
${ }^{1}$ Laboratório de Fisiologia Cardiovascular, D epartamento de Fisiologia, \\ Instituto de Ciências Básicas da Saúde, Universidade Federal do Rio Grande do Sul, \\ Porto Alegre, RS, Brasil \\ ${ }^{2}$ Catedra de Química General e Inorgánica, Facultad de Farmacia y Bioquimica, \\ Universidad de Buenos Aires, Buenos Aires, Argentina \\ ${ }^{3}$ St. Boniface Hospital Research Centre, U niversity of M anitoba, \\ Winnipeg, MB, Canada
}

\section{Correspondence \\ A. Belló-Klein \\ Laboratório de Fisiologia \\ Cardiovascular \\ Departamento de Fisiologia \\ ICBS, UFRGS \\ Rua Sarmento Leite, 500 \\ 90050-170 Porto Alegre, RS \\ Brasil \\ Fax: +55-51-3316-3166 \\ E-mail: belklein@vortex.ufrgs.br \\ Presented at the IV International Symposium on Vasoactive Peptides, Belo Horizonte, MG, Brazil, October 19-21, 2001.}

Research supported by CN Pq, CAPES and FAPERGS.

Received January 3, 2002 Accepted August 6, 2002

\section{Abstract}

The purpose of the present study was to examine myocardial antioxidant and oxidative stress changes in male and female rats in the presence of physiological sex hormone concentrations and after castration. Twenty-four 9-week-old Wistar rats were divided into four groups of 6 animals each: 1) sham-operated females, 2) castrated females, 3) sham-operated males, and 4) castrated males. When testosterone and estrogen levels were measured by radioimmunoassay, significant differences were observed between the castrated and control groups (both males and females), demonstrating the success of castration. Progesterone and catalase levels did not change in any group. Control male rats had higher levels of glutathione peroxidase $(50 \%)$ and lower levels of superoxide dismutase (SOD, 14\%) than females. Control females presented increased levels of SOD as compared to the other groups. After castration, SOD activity decreased by $29 \%$ in the female group and by $14 \%$ in the male group as compared to their respective controls. Lipid peroxidation (LPO) was assessed to evaluate oxidative damage to cardiac membranes by two different methods, i.e., TBARS and chemiluminescence. LPO was higher in male controls compared to female controls when evaluated by both methods, TBARS (360\%) and chemiluminescence (46\%). Castration induced a $200 \%$ increase in myocardial damage in females as determined by TBARS and a $20 \%$ increase as determined by chemiluminescence. In males, castration did not change LPO levels. These data suggest that estrogen may have an antioxidant role in heart muscle, while testosterone does not.

\section{Introduction}

Reactive oxygen species are formed under both physiological and pathological conditions in mammalian tissues. Because of their high reactivity, they may interact with biomolecules, inducing oxidative injury. Reactive oxygen species have been implicated

\section{Key words}

- Catalase

- Glutathione peroxidase

- Lipid peroxidation

- Superoxide dismutase in the pathophysiology of a large number of diseases. Evidence from experimental as well as clinical studies suggests the role of oxidative stress in the pathogenesis of heart dysfunction (1). Protection against oxidative damage is provided by enzymatic and nonenzymatic antioxidant defenses. Recently, the antioxidant effect of sex hormones and 
its cardioprotection have received considerable interest.

Epidemiological studies have demonstrated that premenopausal women appear to be protected from coronary artery disease as compared to men of the same age (2-4). It is also known that in premenopausal women, the incidence of myocardial infarction and other complications related to atherosclerotic disease is lower than in men (5). The incidence of cardiovascular diseases after menopause is similar to that observed in males. These findings suggest a protective role for endogenous estrogen.

After menopause, the coronary artery disease risk is increased by several metabolic and vascular changes, which may be related in part to estrogen deficiency. Estrogen has favorable effects on lipid profiles, endothelial cell function, vascular reactivity and hemostatic factors. Exogenous estrogen protects against atherosclerosis by modulating low-density lipoprotein oxidation, binding free radicals and lowering plasma cholesterol $(6,7)$. Enhanced expression of endothelial nitric oxide synthase and its inducible isoform in the myocardium have also been observed with the administration of exogenous estrogen $(8,9)$.

The benefits of estrogen replacement therapy in reducing risk factors for cardiovascular disease account for only about $50 \%$. This implies that additional mechanisms must exist whereby estrogen exerts a cardioprotective action (10). Previous studies have concentrated mostly on the vascular effects of estrogen, but cardio-protection by estrogen is not necessarily restricted to the vasculature. In a recent review, Babiker and collaborators (11) stated that the benefits of estrogen gradually shift from the vascular system to the myocardium. This view is supported by the fact that functional estrogen receptors have been detected in the myocardium. These receptors regulate the expression of many genes including connexin 43 and heavy chain $\alpha$-myosin (major contrac- tile proteins in the heart) (12). Estrogen has also been shown to be a calcium channel blocker, possibly providing additional cardiovascular protection (13).

In addition to vascular and myocardial effects, estrogen may exert its protective effect via a third property, namely its ability to act as an antioxidant. All estrogens have a phenolic hydroxyl group at position 3 and a methyl group at position 13 . The presence of this phenol group gives estrogen its antioxidant property by scavenging oxygen free radicals. Furthermore, estrogens can induce antioxidant enzyme expression by stimulating the antioxidant defense system (14).

A condition of low iron, such as that caused by menstruation, is another mechanism proposed for cardioprotection in premenopausal women. Reduced levels of iron may result in decreased formation of hydroxyl radicals via the Fenton reaction, and a consequent reduced potential for oxidative damage (15).

The purpose of the present study was to characterize myocardial pro-oxidant and antioxidant profiles in male and female rats to determine whether physiological differences in sex hormone production may cause changes in these parameters. We also determined if the elimination of sex hormones in male and female rats could alter oxidative stress patterns in the myocardium.

\section{Material and Methods}

\section{Experimental protocol}

Nine-week-old Wistar rats (12 males and 12 females) weighing on average $278 \pm 37 \mathrm{~g}$ were divided into four experimental groups: 1) male control submitted to simulated orchidectomy (sham-operation), 2) males castrated according to the procedure of Baker et al. (16), 3) female control submitted to simulated ovariectomy (sham-operation), and 4) females castrated by bilateral ovariectomy performed according to the procedure of 
Baker et al. (16). All females were in the estrous phase at the time of surgery (16).

The stage of the estrous cycle was determined by vaginal swab. The phases observed were: diestrus, when mucus, leukocytes and some nucleated cells were present (2 to 3 days on average); proestrus, when only nucleated cells were present ( $12 \mathrm{~h}$ ); estrus, when only cornified cells were observed $(24 \mathrm{~h}$ - rut phase), and metaestrus, when leukocytes, cornified cells and some nucleated cells were present (16).

\section{Hormonal measurements}

Sex hormone levels (estradiol, progesterone and testosterone) were evaluated in plasma 7 days after surgery by radioimmunoassay using a Biomedicals kit (Biomedical Technologies, Inc., Stoughton, MA, USA).

\section{Preparation of tissue homogenates}

Immediately following blood collection, rats were killed by cervical dislocation and their hearts were removed. The hearts were cooled in ice and homogenized in $1.15 \%$ $(\mathrm{w} / \mathrm{v}) \mathrm{KCl}$ containing $1 \mathrm{mM}$ PMSF. The homogenates were centrifuged at $700 \mathrm{~g}$ for 10 min to discard nuclei and cell debris and the supernatant fraction obtained was frozen at $-70^{\circ} \mathrm{C}$ for further measurements (18).

\section{Antioxidant enzyme activities}

Superoxide dismutase (SOD) activity was determined in heart homogenates by rate inhibition of pyrogallol auto-oxidation at $420 \mathrm{~nm}$. This activity was determined from a standard curve of commercially available SOD (percentage inhibition of pyrogallol auto-oxidation). The enzyme activity was reported as U SOD/mg protein (19).

Glutathione peroxidase activity was measured in heart homogenates by monitoring NADPH oxidation at $340 \mathrm{~nm}$. The reaction medium consisted of $30 \mathrm{nM}$ sodium phos- phate buffer, $\mathrm{pH}$ 7.0, $0.17 \mathrm{mM}$ reduced glutathione, $0.2 \mathrm{U} / \mathrm{ml}$ glutathione reductase, and $0.5 \mathrm{mM}$ tert-butyl hydroperoxide. Glutathione peroxidase activity is reported as nmol min $^{-1}$ mg protein ${ }^{-1}(20)$.

Catalase activity was measured in the homogenates after treatment with Triton X100 by monitoring the decrease in absorption at $240 \mathrm{~nm}$. The reaction medium consisted of $50 \mathrm{mM}$ sodium phosphate buffer, $\mathrm{pH} 7.2$, and $10 \mathrm{mM} \mathrm{H}_{2} \mathrm{O}_{2}$ (21). The results are reported as nmol/mg protein (22).

\section{Lipid peroxidation measurements}

Lipid peroxidation (LPO) was measured by two methods: tert-butyl hydroperoxideinitiated chemiluminescence and thiobarbituric acid reactive substances (TBARS).

In the chemiluminescence method, light emitted from the reaction between tert-butyl hydroperoxide and lipids is measured with a liquid scintillation counter. This counter was adapted to count light emission using a tritium channel (LKB Rack Beta Liquid Scintillation Spectrometer, model 1215, LKBProdukter AB, Bromma, Sweden). The protein content was adjusted to $1 \mathrm{mg} / \mathrm{ml}$ of reaction medium $(120 \mathrm{mM} \mathrm{KCl}, 30 \mathrm{mM}$ sodium phosphate buffer, $\mathrm{pH}$ 7.4) and added to $3 \mathrm{mM}$ tert-butyl hydroperoxide in a final volume of $4 \mathrm{ml}$. The results are reported as counts per minute (cpm)/mg protein (23).

In the TBARS method, absorbance measurements at $535 \mathrm{~nm}$ were used to measure the reaction between thiobarbituric acid and the LPO products, resulting in the formation of a chromogen (Schiff's base). The homogenate was diluted to $1 \mathrm{mg}$ protein $/ \mathrm{ml}$ in $140 \mathrm{mM} \mathrm{KCl}$ and $20 \mathrm{mM}$ potassium phosphate buffer, $\mathrm{pH}$ 7.3, and the same volume of $10 \%$ trichloroacetic acid was added (1:1). The precipitate was removed by centrifugation and the supernatant incubated with $0.67 \%$ thiobarbituric acid for $15 \mathrm{~min}$ at $100^{\circ} \mathrm{C}$. The results are reported as nmol/ mg protein. Commercially available malon- 
aldehyde was used as a standard (24).

\section{Protein measurement}

The protein content of the homogenate was measured by the method of Lowry et al. (25) using bovine serum albumin as a standard.

\section{Statistical analysis}

The data were compared by one-way ANOVA followed by the Student-NewmanKeuls multiple comparison test. Results are reported as means \pm SEM and differences were considered to be significant when $\mathrm{P}<0.05$.

Table 1. Plasma sex hormone levels in different groups of rats.

\begin{tabular}{lcccccc}
\hline Sex hormone & \multicolumn{2}{c}{ Females } & & \multicolumn{2}{c}{ Males } \\
\cline { 2 - 3 } \cline { 5 - 6 } & Control & Castrated & & Control & Castrated \\
\hline Estradiol $(\mathrm{pg} / \mathrm{ml})$ & $44.30 \pm 5.34$ & ND* & & NA & NA \\
Progesterone $(\mathrm{ng} / \mathrm{ml})$ & $5.72 \pm 0.96$ & $6.58 \pm 1.20$ & & NA & NA \\
Testosterone $(\mathrm{ng} / \mathrm{ml})$ & $\mathrm{NA}$ & $\mathrm{NA}$ & & $0.67 \pm 0.09$ & ND*
\end{tabular}

Data are reported as means \pm SEM for six animals in each group. NA, not analyzed; ND, not detected.

$* \mathrm{P}<0.001$ compared to the control group of the same sex (Student t-test).

Table 2. Antioxidant activity in cardiac muscle homogenates from different groups of rats.

\begin{tabular}{|c|c|c|c|c|}
\hline \multirow{2}{*}{$\begin{array}{l}\text { Antioxidant } \\
\text { enzymes }\end{array}$} & \multicolumn{2}{|c|}{ Females } & \multicolumn{2}{|c|}{ Males } \\
\hline & Control & Castrated & Control & Castrated \\
\hline $\begin{array}{l}\text { SOD (U/mg protein) } \\
(F=26.20)\end{array}$ & $38.82 \pm 0.83$ & $27.60 \pm 1.34 *$ & $33.38 \pm 0.87 *$ & $28.51 \pm 1.33^{*}$ \\
\hline $\begin{array}{l}\mathrm{GPx}\left(\mathrm{nmol} \mathrm{min}^{-1} \mathrm{mg}\right. \\
\left.\text { protein }{ }^{-1}\right)(\mathrm{F}=4.07)\end{array}$ & $67.10 \pm 5.64$ & $78.28 \pm 5.71$ & $100.59 \pm 6.31^{*}$ & $94.09 \pm 11.06$ \\
\hline $\begin{array}{l}\mathrm{CAT}(\mathrm{pmol} / \mathrm{mg} \\
\text { protein) }(\mathrm{F}=2.30)\end{array}$ & $31.60 \pm 1.44$ & $25.50 \pm 1.76$ & $25.40 \pm 1.39$ & $28.10 \pm 2.76$ \\
\hline
\end{tabular}

Data are reported as means \pm SEM for six animals in each group. SOD, superoxide dismutase; GPx, glutathione peroxidase; CAT, catalase.

$* \mathrm{P}<0.05$ compared to the control group of the same sex (ANOVA).

\section{Results}

Sex hormone data are shown in Table 1. As expected, testosterone levels in the castrated male group and estrogen levels in the castrated female group were undetectable. No significant differences in progesterone levels were detected between control and castrated female groups (Table 1). These data confirm the efficacy of surgical castration.

Enzymatic antioxidant defense mechanisms were evaluated in the myocardium of male and female rats. The activity of SOD, which detoxifies the superoxide anion, was lower (14\%) in the male control group than in the female control group $(\mathrm{P}<0.05)$. After castration, SOD activity was decreased by $29 \%(\mathrm{P}<0.001)$ in the female group and by $14 \%(\mathrm{P}<0.05)$ in the male group when compared to their respective controls (Table 2). Glutathione peroxidase, an enzyme that metabolizes $\mathrm{H}_{2} \mathrm{O}_{2}$ and organic peroxides, was $50 \%$ higher in the male control group than in the female control group $(\mathrm{P}<0.05)$. Castration induced a small nonsignificant increase in glutathione peroxidase activity in females and a similar decrease in males (Table 2). The male control group also showed a $20 \%$ nonsignificant reduction in the activity of catalase, an enzyme responsible for metabolizing hydrogen peroxide. No significant differences were found in catalase activity when comparing the male and female castrated groups (Table 2).

In order to detect increased oxidative damage to cardiac tissue, LPO was assessed by two methods, i.e., TBARS and chemiluminescence. LPO was significantly higher in male controls than in female controls both by the TBARS (360\%) and chemiluminescence (46\%) methods (Figure 1A,B; $\mathrm{P}<0.001$ and $\mathrm{P}<0.01$, respectively).

In females, castration caused a $200 \%$ increase in LPO $(\mathrm{P}<0.01)$ as determined by TBARS (Figure 1A) and a $20 \%$ increase $(\mathrm{P}<0.05)$ as determined by chemiluminescence (Figure 1B). Male LPO levels did not 
change after castration (Figure 1A,B).

\section{Discussion}

While there have been many studies on the relationship between sex hormones, LPO and antioxidants, the present study is the first to examine these parameters in the presence of physiological hormone concentrations in myocardial tissue. Most of the previous experiments were conducted on postmenopausal women or castrated female animals on estrogen replacement therapy (26).

One of the aims of the present study was to evaluate the oxidative stress and antioxidant defenses in the myocardium of male and female control rats. Oxidative stress was assessed by LPO. A wide variety of procedures have been used to measure LPO, but they are indirect and lack sensitivity, selectivity as well as practicability. Furthermore, there is no ideal method to measure LPO, and the literature suggests using more than one to improve accuracy. Therefore, if the results obtained with the use of different techniques are concordant, then the results are acceptable. In the present study, the results obtained by TBARS and chemiluminescence were in agreement. Lower levels of TBARS and chemiluminescence were observed in the female control group (Figure 1A,B), which presented higher estrogen levels, as compared to the male control group. The reduction in LPO in the presence of estrogen confirms the antioxidant action of this hormone and its scavenger properties, which minimize free radical damage to membrane lipids (27).

Myocardial catalase was not different between male and female control groups in terms of antioxidant activity (Table 2). This finding may mean that hydrogen peroxide production in the heart is not influenced by sex hormones, since this enzyme is specific for hydrogen peroxide. However, with respect to superoxide dismutase, female rat hearts have a higher activity than male con- trol hearts (Table 2). Since females have enhanced SOD activity (which is an important antioxidant enzymatic defense) and in view of the non-enzymatic defense offered by estrogen, oxidative stress was kept under control, as shown by the LPO data. Although glutathione peroxidase activity was decreased in females as compared to male controls, the pro-oxidant/antioxidant balance was in the favor of the antioxidants and the oxidative damage was reduced in females.

Glutathione peroxidase enhancement in male hearts, that do not have estrogen protection, is not enough to balance free radical production. This appears to be an example of oxidative stress-induced up-regulation of an antioxidant enzyme (28).

The antioxidant potential of various steroid hormones (estriol, estradiol, estrone, progesterone, testosterone, androstenedione, cortisol and others) have been evaluated and it was shown that estrogens, especially estriol and estradiol, are natural antioxidants, while the other steroids do not present significant antioxidant activity (29).

The other aim of the present study was to determine whether the removal of sex hormones could affect the oxidative stress pattern observed under physiological conditions.

Bilateral castration was performed in male

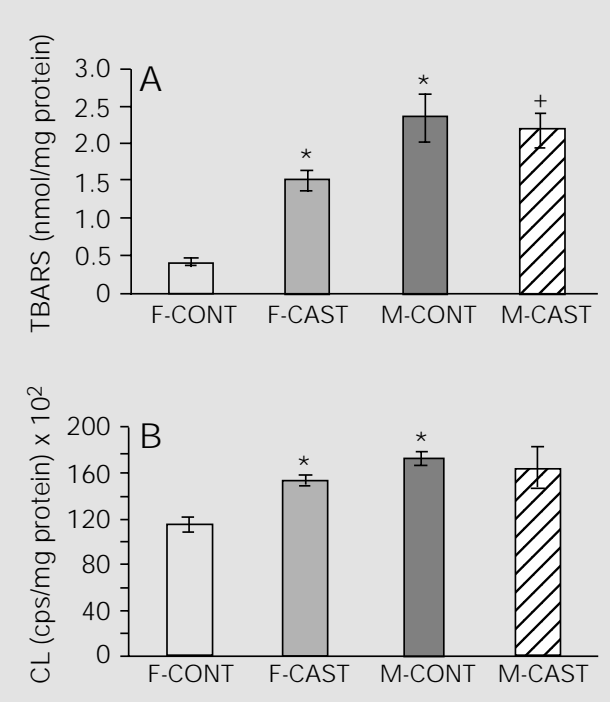

Figure 1. Lipid peroxidation. A, Thiobarbituric acid reactive substances (TBARS) in heart muscle homogenates from different groups ( $F=18.53)$. $\mathrm{B}$, Chemiluminescence $(\mathrm{CL})$ applied to the heart muscle homogenates of different experimental groups $(F=6.46)$. $* \mathrm{P}<0.05$ compared to the female control group. ${ }^{+} \mathrm{P}<0.05$ compared to the castrated female group (ANOVA). $\mathrm{M}=$ male, $\mathrm{F}=$ female, CONT = control, CAST $=$ castrated. Data are reported as means \pm SEM for six animals in each group. 
and female rats, and 7 days after surgery, hormonal levels were quantified. A marked increase in LPO was observed in females after castration, thus approaching male values (Figure 1A,B). This finding suggests that the antioxidant potential of estrogen may be an important contributor to the cardiovascular protection of the hormone, in addition to its regulatory effects on LDL oxidation, endothelium-derived relaxing factors and antioxidant enzymes (30). Seven days postcastration were enough to reduce sex hormones to undetectable levels; however, this period may not be long enough to change enzyme activity. This may be the case for catalase, which is not affected by castration. Another possibility is that catalase activity in the heart is so low that small changes were not detected (28).

SOD seems to be more sensitive to hormonal changes. In the present study, we found a decrease in SOD activity when both estrogen and testosterone were removed. Others have reported changes in SOD activity in the presence of variations in estrogen $(26,30,31)$. Most of these studies demonstrated a decrease in SOD activity when exogenous estradiol was administered (32, 33). This apparent discrepancy may be due to the fact that some of those experiments were performed on cell cultures or on previously castrated animals on hormone replacement therapy with estrogen concentrations much higher (micromolar) than physiological levels (nanomolar). However, there was also an increase in SOD activity when exogenous $17 ß$-estradiol was administered (34). We have demonstrated that long-term depletion of ovarian hormones (21 and 28 days) induces an increase in myocardial SOD activity (Barp J, Morgan-Martins MI, Marroni C, Vercelino R, Fernandes TRG and BellóKlein A, unpublished data). Decreased superoxide anion $\left(\mathrm{O}_{2}{ }^{--}\right)$production by the endothelium in response to estrogen is considered to contribute to the vascular protective properties of estrogen (31). This is because $\mathrm{O}_{2}{ }^{- \text {- }}$ can inactivate nitric oxide and thus lead to endothelial dysfunction (35). In this study, SOD activity was also found to be decreased after short-term depletion of the male sex hormone, suggesting that testosterone could also influence the enzymatic defense system. There is some information on oxidative stress in men showing a pro-oxidant effect of testosterone (36).

Previous studies from our laboratory have indicated the need to consider seasonal variations in antioxidant enzyme activities evaluated by LPO (37). The present data emphasize the fact that gender differences should be considered when studying oxidative stress. Our results showed apparent changes in myocardial oxidative stress and in antioxidants between male and female controls as well as after castration.

\section{References}

1. Singal PK, Khaper N, Palace V \& Kumar D (1998). The role of oxidative stress in the genesis of heart disease. Cardiovascular Research, 40: 426-432.

2. Wenger NK, Speroff L \& Packard B (1993). Cardiovascular health and disease in women. New England J ournal of Medicine, 329: 247-256.

3. Matthews KA, Meilahn E, Kuller LH, Kelsey SF, Caggiula AW \& Wing RR (1989). Menopause and risk factors for coronary heart disease. New England J ournal of Medicine, 321: 641-646.

4. Nabulsi AA, Folsom AR \& White A (1993).
Association of hormone replacement therapy with various cardiovascular risk factors in postmenopausal women. New England J ournal of Medicine, 328: 10691075.

5. Ganong WF (1999). Review of Medical Physiology. 19th edn. Appleton \& Lange, East Norwalk, CT, USA.

6. Kuhl H (1994). Cardiovascular effects and estrogen/gestagen substitution therapy. Therapeutische Umschau, 51: 748-754.

7. Maffei S \& De Caterina R (1996). Hormone replacement therapy and cardiovascular risk. Giornale Italiano di Cardiologia,
26: 899-940.

8. Farhat MY, Lavigne MC \& Ramwell PW (1996). The vascular protective effect of estrogen. FASEB J ournal, 10: 615-624.

9. Nuedling S, Kahlert S, Loebbert K, Doevendans PA, Meyer R, Vetter $\mathrm{H}$ \& Grohé C (1999). 17ß-Estradiol stimulates expression of endothelial and inducible NO synthase in rat myocardium in vitro and in vivo. Cardiovascular Research, 43: 666-674.

10. Kuroski de Bold ML (1999). Estrogen, natriuretic peptides and the renin-angiotensin system. Cardiovascular Research, 
41: 524-531.

11. Babiker FA, De Windt $L$ J , van Eickels $M$, Grohé $\mathrm{C}$, Meyer R \& Doevendans PA (2002). Estrogenic hormone action in the heart: regulatory network and function. Cardiovascular Research, 53: 709-719.

12. Grohé $\mathrm{C}$, Kahlert S, Loebbert K, Stimpel M, Karas RH, Vetter H \& Neyses L (1997). Cardiac myocytes and fibroblasts contain functional estrogen receptors. FEBS Letters, 416: 107-112.

13. Collins $P$, Beale CM \& Rosano GMC (1996). Oestrogen as a calcium channel blocker. European Heart J ournal, 17 (Suppl D): 27-31.

14. Massafra C, De Felice C, Gioia D \& Buonocore G (1998). Variations in erythrocyte antioxidant glutathione peroxidase activity during the menstrual cycle. Clinical Endocrinology, 49: 63-67.

15. Sullivan MJ , Green HJ \& Cobb FR (1991). Altered skeletal muscle metabolic response to exercise in chronic heart failure: relation to skeletal muscle aerobic enzyme activity. Circulation, 84: 15971607.

16. Baker $\mathrm{HJ}$, Lindsey J R \& Weisbroth $\mathrm{SH}$ (1979). The Laboratory Rat. Vol. I, Biology and Diseases. Academic Press, New York, NY, USA.

17. Genuth SM (1993). The endocrine system. In: Berne RM \& Levy MN (Editors), Physiology. 3rd edn. Mosby-Year Book, Inc., St. Louis, MO, USA.

18. Llesuy SF, Milei J , Molina $\mathrm{H}$, Boveris A \& Milei S (1985). Comparison of lipid peroxidation and myocardial damage induced by adriamycin and 4'-epiadriamycin in mice. Tumori, 71: 241-249.

19. Marklund S (1985). Pyrogallol autoxidation. In: Greenwald RA (Editor), Handbook of Methods for Oxygen Radical Research. CRC Press, Boca Raton, FL, USA, 243247.

20. Flohé L \& Gunzler WA (1984). Assay of glutathione peroxidase. Methods in Enzy- mology, 105: 114-121.

21. Chance B, Sies H \& Boveris A (1979). Hydroperoxide metabolism in mammalian organs. Physiological Reviews, 59: 527625.

22. Boveris A \& Chance B (1973). The mitochondrial generation of hydrogen peroxide. Biochemical J ournal, 134: 707-716.

23. Gonzalez Flecha B, Llesuy $S \&$ Boveris A (1991). Hydroperoxide-initiated chemiluminescence: an assay for oxidative stress in biopsies of liver, heart and muscle. Free Radical Biology and Medicine, 10: 41-47.

24. Buege J Á \& Aust SD (1978). Microsomal lipid peroxidation. Methods in Enzymology, 52: 302-309.

25. Lowry $\mathrm{OH}$, Rosebrough $\mathrm{AL}$, Farr $\mathrm{AL} \&$ Randall R (1951). Protein measurement with the Folin phenol reagent. J ournal of Biological Chemistry, 193: 265-275.

26. Akcay T, Dincer Y, Kayali R, Colgar U, Oral E \& Cakatay U (2000). Effects of postmenopausal women. J ournal of Toxicology and Environmental Health, Part A, 59: 1-5.

27. Niki E \& Nakano M (1990). Estrogens as antioxidants. Methods in Enzymology, 186: 330-333.

28. Halliwell B \& Gutteridge J CM (1999). Free Radicals in Biology and Medicine. 3rd edn. Oxford University Press, New York, NY, USA.

29. Mooradian AD (1993). Antioxidant properties of steroides. J ournal of Steroid Biochemistry and Molecular Biology, 45: 509511.

30. Dantas APV, Scivoletto R, Fortes ZB, Nigro D \& Carvalho MHC (1999). Influence of female sex hormones on endothelium-derived vasoconstrictor prostanoid generation in microvessels of spontaneously hypertensive rats. Hypertension, 34: 914-919.

31. Barbacanne MA, Rami J, Michel J B, Souchard J P, Philippe M, Besombes J P, Bayard F \& Arnal J F (1999). Estradiol in- creases rat aorta endothelium-derived relaxing factor (EDRF) activity without changes in endothelial NO synthase gene expression: possible role of decreased endothelium-derived superoxide anion production. Cardiovascular Research, 41: 672-681.

32. Kenaley J A \& Ji LL (1991). Antioxidant enzyme activity during prolonged exercise in amenorrheic and eumenorrheic athletes. Metabolism: Clinical and Experimental, 40: 88-92.

33. Arnal J F, Clamens S, Pechet C, Negre SA, Allera C, Girolami J P, Salvayre R \& Bayard $F$ (1996). Ethinylestradiol does not enhance the expression of nitric oxide synthase in bovine endothelial cells but increases the release of bioactive nitric oxide by inhibiting superoxide anion production. Proceedings of the National Academy of Sciences, USA, 93: 4108-4113.

34. Oberley TD, Shultz J L \& Oberley LW (1994). In vivo modulation of antioxidant enzyme levels in normal hamster kidney and estrogen-induced kidney tumor. Free Radical Biology and Medicine, 16: 741751.

35. Nakazono K, Watanabe N, Matsuno K, Sasaki J , Sato T \& Inoue M (1991). Does superoxide underlie the pathogenesis of hypertension? Proceedings of the National Academy of Sciences, USA, 88: 10045-10048.

36. Dincer Y, Ozen E, Kadioglu P, Hatemi H \& Akcay T (2001). Effect of sex hormones on lipid peroxidation in women with polycystic ovary syndrome, healthy women, and men. Endocrine Research, 27: 309316.

37. Belló-Klein A, Morgan-M artins MI, Barp J , Llesuy S, Belló AA \& Singal PK (2000). Circaannual changes in antioxidants and oxidative stress in the heart and liver in rats. Comparative Biochemistry and Physiology. Part C, 126: 203-208. 